\title{
Clinical Relevance of Classification According to Weaning Difficulty
}

\author{
Alexandre Tonnelier MD, Jean-Marie Tonnelier MD, Emmanuel Nowak MD, \\ Christophe Gut-Gobert MD, Gwenaël Prat MD, Anne Renault MD, \\ Jean-Michel Boles MD, and Erwan L'Her MD PhD
}

\begin{abstract}
OBJECTIVE: To evaluate the clinical relevance of the weaning from mechanical ventilation classification system derived from the 2005 international consensus conference, in patients who receive mechanical ventilation for more than $\mathbf{4 8}$ hours, and evaluate its correlation with prognosis. METHODS: We conducted a retrospective cohort study in a 12-bed intensive care unit (ICU) in a teaching hospital. We included patients who required $>\mathbf{4 8}$ hours of mechanical ventilation and who passed a spontaneous breathing trial (SBT). Weaning and sedation were monitored according to standardized protocol-directed procedures. We collected data on physiological characteristics, mechanical ventilation duration, ICU and hospital stay, and mortality from the medical records database. We assessed one-year mortality with a prospective, standardized method. Multivariate logistic regression was performed to evaluate the association between weaning categories and outcome. RESULTS: We included 329 ventilation episodes, in which 115 patients passed at least one SBT. Thirty-four patients (30\%) succeeded in their first SBT (simple weaning group), 47 patients (40\%) succeeded in their 2nd or 3rd SBT or in less than 7 days of weaning (the difficult weaning group), and 34 patients $(30 \%)$ required more than 3 SBTs or more than 7 days of weaning (the prolonged weaning group). There were significant differences in ICU and hospital mortality between the simple, difficult, and prolonged-weaning groups. Prolonged weaning was an independent risk factor for longer ICU stay (odds ratio $15.11,95 \%$ CI 1.61-141.91, $P=.01$ ) and hospital mortality (odds ratio 3.66, 95\% CI 0.99-13.51). However, the weaning process did not impact one-year mortality (odds ratio 2.61, 95\% CI 0.82-8.35). CONCLUSIONS: The new weaning classification system is clinically relevant and correlates to ICU and hospital mortality, but not to one-year mortality. Key words: mechanical ventilation; ICU; weaning; classification; prognosis; one-year mortality. [Respir Care 2011;56(5):583-590. (C) 2011 Daedalus Enterprises]
\end{abstract}

\footnotetext{
Alexandre Tonnelier MD, Jean-Marie Tonnelier MD, Gwenaël Prat MD, Anne Renault MD, Jean-Michel Boles MD, and Erwan L'Her MD PhD are affiliated with Réanimation Médicale, Pôle Urgences-AnesthésieRéanimation, Centre Hospitalier Universitaire Brest, Brest, France. Drs Tonnelier, Boles, and L'Her are also affiliated with Faculté de Médecine et des Sciences de la Santé, Université de Brest, Brest, France, and with Université Européenne de Bretagne, Rennes, France. Emmanuel Nowak MD is affiliated with Centre Hospitalier Universitaire Brest, Centre d'Investigation Clinique Institut National de la Santé et de la Recherche Médicale (INSERM), Brest, France. Christophe Gut-Gobert MD is affiliated with Département de Médecine Interne et Pneumologie, Pôle Vasculaire, Centre Hospitalier Universitaire Brest, Brest, France. Dr L'Her is also affiliated with Laboratoire de Traitement de l'Information Médicale (LATIM) Institut National de la Santé et de la Recherche Médicale (INSERM U650), Université de Bretagne Occidentale, Brest, France.
}

\section{Introduction}

Endotracheal intubation and mechanical ventilation are common procedures in intensive care units (ICUs). Although it is life-saving for patients with acute respiratory failure, mechanical ventilation is also associated with serious complications, the incidence of which is directly related to the duration of ventilation, ${ }^{1-4}$ as is the

See the Related Editorial on Page 716

cost of ICU stay: $6 \%$ of mechanically ventilated patients require prolonged ventilation, but their costs represent $37 \%$ of ICU expenses. ${ }^{5,6}$ Optimizing weaning is mandatory to shorten mechanical ventilation, because the weaning period represents $40 \%$ of the overall ventilation period. ${ }^{7-10}$ 
In 2005, during the international consensus conference on weaning from mechanical ventilation, a new patient classification system according to the weaning process was proposed. Patients are classified into 3 groups, according to the duration of weaning and the number of spontaneous breathing trials (SBTs) preceding successful extubation: ${ }^{11}$

- Simple weaning: Successfully extubated after the first SBT

- Difficult weaning: Successfully extubated after 2 or 3 SBTs, or weaning took less than 7 days from the first SBT to successful extubation

- Prolonged weaning: Not weaned after more than 3 SBTs, or weaning takes more than 7 days

That classification system is based on clinician experience but not on any literature data. Whether it correlates with outcome has been investigated in only one study, and there are no data on long-term outcomes. ${ }^{12}$ Since the classification is based only on expert opinion, the jury noted that "the proposed definition of the weaning process and the groups of patients who undergo weaning need to receive careful testing and scrutiny. Studies of the patients' outcomes in the difficult weaning and the prolongedweaning groups are needed". ${ }^{11}$ We therefore conducted a retrospective review of patients who received mechanical ventilation for more than 48 hours, during a one-year period in a teaching ICU, to evaluate the clinical relevance of the classification system and its correlation with prognosis.

\section{Methods}

\section{Study Design}

This was a retrospective cohort study of patients in the 12-bed ICU of a teaching hospital. Patient data were extracted from a medical records database, for all patients who required mechanical ventilation between January 1 and December 31, 2004. The study was approved by our local ethics committee.

\section{Patient Selection}

We included patients who received more than 48 hours of mechanical ventilation and who passed an SBT, as

\footnotetext{
The authors have disclosed no conflicts of interest.
}

Correspondence: Erwan L’Her MD PhD, Réanimation Médicale, Centre Hospitalier Universitaire de la Cavale Blanche, 29609 Brest, France. E-mail: erwan.lher@chu-brest.fr.

DOI: $10.4187 /$ respcare. 00842 defined in the weaning protocol (see below). We excluded patients with tracheotomy prior to admission and those who died before the start of weaning.

Weaning was conducted according to a standardized nurse-driven protocol that we had implemented several years before and that significantly reduced the duration of mechanical ventilation and ICU stay. ${ }^{13}$ Daily the nurses screened patients for the SBT eligibility criteria: $\mathrm{F}_{\mathrm{IO}_{2}}<0.50$, PEEP $<5 \mathrm{~cm} \mathrm{H}_{2} \mathrm{O}$, no vasopressor infusion, no sedative infusion, and response to simple orders. Physician approval for initiation of SBT was not required. The planned SBT duration was $90 \mathrm{~min}$, and SBTs were always performed with a T-piece. The SBT was terminated early and considered a failure if any of the following occurred: $\mathrm{S}_{\mathrm{pO}_{2}}<90 \%$, respiratory rate $>35$ breaths/min, heart rate or systolic arterial pressure change of $>20 \%$, or patient agitation. An SBT was considered successful if the patient breathed spontaneously for $90 \mathrm{~min}$. If SBT succeeded, the physician was asked to approve discontinuation of mechanical ventilation. Extubation was performed if cough was subjectively considered sufficient, and if a leak test was considered positive (inspiratory and/or expiratory air leak after cuff deflation). If the SBT was not well tolerated, the variables that caused the failure were recorded and the patient was returned to his or her prior ventilator settings and mode, on either pressure support ventilation or volume assist control ventilation, then screened again the following day (Fig. 1). According to the consensus criteria, weaning was considered successful if no re-intubation was needed within 48 hours of extubation.

In addition to the weaning protocol, we also used a nurse-driven directed sedation protocol that is based on the Ramsay sedation scale. ${ }^{14}$ The dosage of sedatives was regularly lowered to obtain the clinical objective, usually twice daily, set by the attending physician.

\section{Clinical and Outcome Data}

The following data were collected for each patient: physiological characteristics, mechanical ventilation indication, sedation and mechanical ventilation duration, ICU stay, hospital stay, mechanical ventilation duration before the start of weaning (days from intubation to first SBT), SBT number, first $3 \mathrm{SBT}$, subsequent need for tracheotomy, ventilator-associated pneumonia incidence, self-extubation episodes, vital signs at ICU discharge, hospital discharge, and one year after hospital discharge. Outcomes and oneyear mortality were prospectively assessed at the time of analysis, with a standardized process that collects the information via telephone call to the patient's general practitioner or the patient's birth-town city hall. 


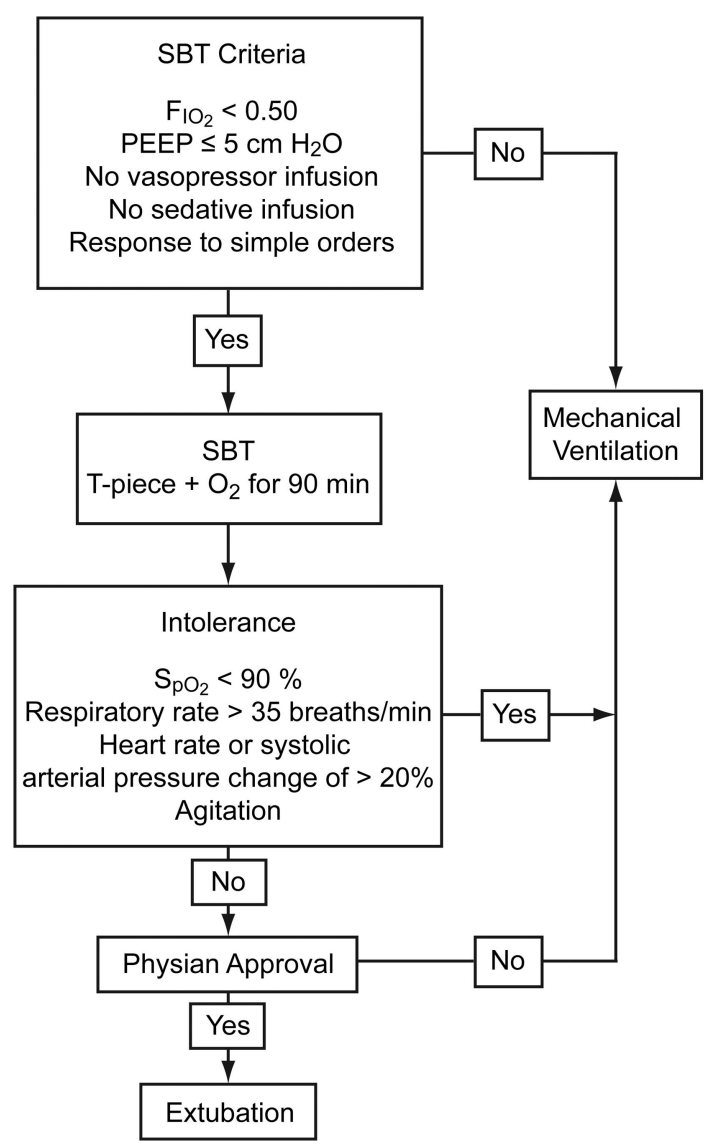

Fig. 1. Mechanical ventilation weaning protocol. Daily screening identified patients eligible for weaning. A spontaneous breathing trial (SBT) was considered successful when the patient could breathe spontaneously for $90 \mathrm{~min}$ without clinical intolerance. With those patients the physicians were then asked to approve discontinuation of mechanical ventilation. If the SBT was not tolerated, the patient was returned to their prior ventilator settings and screened again the next day.

\section{Statistical Analysis}

The 3 weaning groups were compared for each variable. We used the Kruskal-Wallis test for continuous variables, and chi-square or Fisher test (when chi-square test conditions of use were not satisfied) for categorical variables. When groups were statistically different for a variable, each group was compared to another with Bonferroni correction for multiple tests. Continuous variables are expressed as mean $\pm \mathrm{SD}$, and categorical variables as percentages. $P<.05$ was considered statistically significant. We used multivariate logistic regression to explore the association between weaning categories and mortality. None of the simple-weaning patients died in the ICU or hospital, so multivariate logistic regression was not possible with the simpleweaning group as the reference. Therefore, we com-

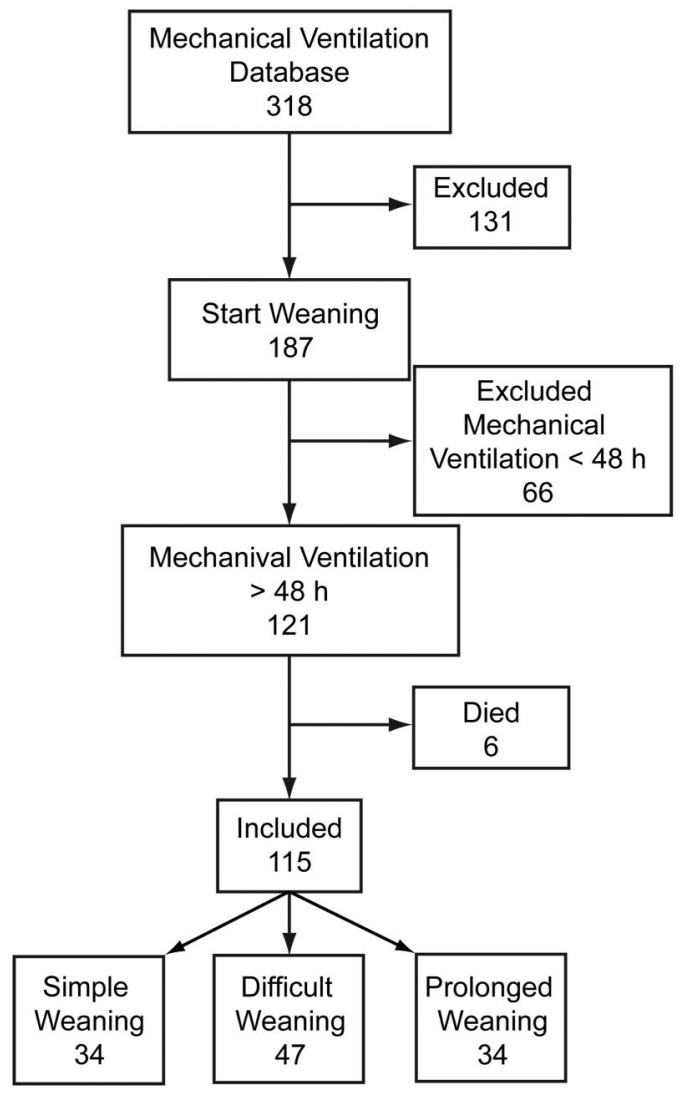

Fig. 2. Study flowchart.

pared the prolonged-weaning patients to the simpleweaning or difficult-weaning patients. In the univariate analysis (not shown), covariates with a $P<.15$ for at least one outcome (ICU stay, hospital stay, or one-year mortality) or clinically relevant were included in the multivariate logistic model. The analyses were made with statistics software (R 2.8.1, R Foundation for Statistical Computing, Vienna, Austria).

\section{Results}

During the study period, 315 patients admitted to our ICU required invasive or noninvasive mechanical ventilation. Three patients were admitted and ventilated twice, and those patients were individually considered as new patients for each admission, so we considered 318 ventilation episodes (Fig. 2). We excluded 131 patients from the analysis: 22 who only required noninvasive ventilation; 4 who were already tracheostomized on admission; 8 who were lost to follow-up; and 97 who died prior to the start of weaning. One-hundred eightyseven patients passed at least one SBT, of which 121 needed mechanical ventilation for more than 48 hours. Six patients died during weaning, so we included 115 


\section{Clinical Relevance of Classification According to Weaning Difficulty}

Table 1. Demographics and Indications for Mechanical Ventilation

\begin{tabular}{lc}
\hline \hline Patients $(n)$ & 115 \\
Male-to-female ratio & 2.3 \\
Age (y) & $56 \pm 18$ \\
SAPS II score & $54 \pm 22$ \\
Admission Diagnosis, no. (\%) & \\
ARF on COPD & $11(10)$ \\
Heart failure & $3(3)$ \\
Pneumonia & $17(15)$ \\
Acute pulmonary embolism & $1(1)$ \\
Others & $4(3)$ \\
Sepsis & $12(10)$ \\
Scheduled surgery & $4(3)$ \\
Non-trauma coma & $37(32)$ \\
$\quad$ Toxic & $11(9)$ \\
$\quad$ Metabolic & $6(5)$ \\
$\quad$ Neurologic & $18(16)$ \\
Trauma-related coma & $14(12)$ \\
Cardiac arrest & $11(10)$ \\
Other & $3(3)$ \\
& \\
\hline \pm values are mean \pm SD. & \\
ARF = acute respiratory failure & \\
SAPS = Simplified Acute Physiology Score & \\
\hline
\end{tabular}

patients in the final cohort: $34(30 \%)$ in the simpleweaning group, 47 (40\%) in the difficult-weaning group, and $34(30 \%)$ in the prolonged-weaning group.
Table 1 shows the demographics and indications for initiation of mechanical ventilation. Table 2 shows the physiological variables, duration of ventilation and sedation, ICU and hospital stay, and weaning data, stratified by weaning group. The physiological characteristics were similar in the 3 groups. Ventilation duration and ICU stay significantly increased from the simple to the difficult to the prolonged weaning groups. Ventilation duration before weaning was shorter in the simple and difficultweaning groups than in the prolonged-weaning group. However, sedation duration, ventilation duration hospital stay, and ventilation duration before the first SBT did not differ between the simple-weaning group and the difficult-weaning group. Ventilator-associated pneumonia incidence was highest in the prolonged-weaning group.

Table 3 shows the ICU mortality, hospital mortality, and one-year mortality. ICU mortality and hospital mortality were significantly higher in the prolongedweaning group, but one-year mortality did not significantly differ between the weaning groups. Eight patients were lost to follow-up and one-year outcome evaluation. Multivariate logistic regression identified prolonged weaning as a major independent risk factor for ICU mortality and, at a lesser degree, for hospital mortality (Table 4). Weaning category, however, had no influence on one-year mortality (Table 5). There was a

Table 2. Physiological Variables, Duration of Ventilation and Sedation, ICU and Hospital Stay, and Weaning Data

\begin{tabular}{|c|c|c|c|c|}
\hline & $\begin{array}{c}\text { Simple } \\
\text { Weaning }\end{array}$ & $\begin{array}{l}\text { Difficult } \\
\text { Weaning }\end{array}$ & $\begin{array}{l}\text { Prolonged } \\
\text { Weaning }\end{array}$ & $P$ \\
\hline Male-to-female ratio & 2.1 & 2.9 & 1.8 & .62 \\
\hline Age (y) & $54 \pm 18$ & $55 \pm 16$ & $60 \pm 17$ & .30 \\
\hline SAPS II score & $53 \pm 16$ & $53 \pm 19$ & $56 \pm 16$ & .66 \\
\hline ICU stay (d) & $10.1 \pm 8.6$ & $16.2 \pm 15.1^{*}$ & $30.1 \pm 25.2 \dagger \neq$ & $<.001$ \\
\hline Hospital stay (d) & $26.6 \pm 17.5$ & $33.8 \pm 38.1$ & $61.9 \pm 85.0 \dagger \neq$ & .01 \\
\hline Sedation days (d) & $4.1 \pm 6.4$ & $4.8 \pm 5.5$ & $8.1 \pm 9.1 \dagger$ & .01 \\
\hline Ventilation days (d) & $7.4 \pm 7.9$ & $9.7 \pm 7.5^{*}$ & $22.4 \pm 20.8 \dagger \neq$ & $<.001$ \\
\hline Ventilation days before weaning (d) & $6.4 \pm 8.2$ & $6.7 \pm 6.8$ & $10.3 \pm 9.3 \dagger \neq$ & .01 \\
\hline \multicolumn{5}{|l|}{ SBT duration (min) } \\
\hline $1 \mathrm{st}$ & $104 \pm 29$ & $74 \pm 59 *$ & $49 \pm 39 \dagger$ & $<.001$ \\
\hline 2nd & NA & $89 \pm 45$ & $59 \pm 39 \ddagger$ & .01 \\
\hline $3 \mathrm{rd}$ & NA & $96 \pm 19$ & $76 \pm 55 \ddagger$ & .06 \\
\hline Weaning days (d) & NA & $3 \pm 1$ & $9 \pm 5 \ddagger$ & $<.001$ \\
\hline Extubation failure, no. (\%) & $0(0)$ & $4(9)$ & $8(24)$ & .03 \\
\hline Re-intubation, no. (\%) & $0(0)$ & $3(6)$ & $5(15)$ & .24 \\
\hline Ventilator-associated pneumonia, no. (\%) & $2(6)$ & $10(21)$ & $21(62) \dagger \dagger$ & $<.001$ \\
\hline \multicolumn{5}{|l|}{$\begin{array}{l}\text { values are mean } \pm \text { SD. } \\
\text { * Significant difference for simple versus difficult weaning. } \\
\dagger \text { Significant difference for simple versus prolonged weaning. } \\
\text { ‡ Significant difference for difficult versus prolonged weaning. } \\
\text { ARF }=\text { acute respiratory failure } \\
\text { SAPS = Simplified Acute Physiology Score } \\
\text { NA }=\text { not applicable }\end{array}$} \\
\hline
\end{tabular}




\section{Clinical Relevance of Classification According to Weaning Difficulty}

Table 3. Outcomes

\begin{tabular}{lccccc}
\hline \hline & $\begin{array}{c}\text { Patients } \\
\text { Included } \\
115\end{array}$ & $\begin{array}{c}\text { Simple } \\
\text { Weaning } \\
34\end{array}$ & $\begin{array}{c}\text { Difficult } \\
\text { Weaning } \\
47\end{array}$ & $\begin{array}{c}\text { Prolonged } \\
\text { Weaning } \\
34\end{array}$ & $P^{*}$ \\
\hline $\begin{array}{l}\text { Followed up at } \\
\text { one year }\end{array}$ & 107 & 32 & 44 & 31 & NA \\
$\begin{array}{l}\text { ICU mortality, } \\
\text { no. } \%)\end{array}$ & $7(6)$ & $0(0)$ & $1(2)$ & $6(18)$ & .01 \\
$\begin{array}{l}\text { Hospital mortality, } \\
\text { no. }(\%)\end{array}$ & $12(15)$ & $0(0)$ & $5(11)$ & $7(21) \dagger$ & .01 \\
$\begin{array}{l}\text { One year mortality, } \\
\text { no. } \%)\end{array}$ & $35(33)$ & $7(29)$ & $15(34)$ & $13(42)$ & .23 \\
$\begin{array}{l}* \text { Significant difference for simple versus prolonged weaning. } \\
\text { NA = not applicable }\end{array}$ & & & & & \\
ICU = intensive care unit & & & & & \\
\hline
\end{tabular}

Table 4. Logistic Regression Model for the Association of the Prolonged Weaning Category, ICU, Hospital, and One-Year Mortality

\begin{tabular}{lcc}
\hline \hline & $\begin{array}{c}\text { Odds Ratio } \\
(95 \% \text { CI })\end{array}$ & $P$ \\
\hline ICU Mortality & 1 (reference) & \\
$\quad$ Simple or difficult weaning & $15.11(1.61-141.91)$ & .01 \\
Prolonged weaning & $1.00(0.90-1.11)$ & .97 \\
Ventilation duration before weaning & $1.07(0.99-1.17)$ & .08 \\
Age & $0.99(0.93-1.05)$ & .65 \\
SAPS II score & & \\
Hospital Mortality & $1($ reference $)$ & \\
Simple or difficult weaning & $3.66(0.99-13.51)$ & .05 \\
Prolonged weaning & $1.02(0.96-1.09)$ & .53 \\
Ventilation duration before weaning & $1.03(0.98-1.08)$ & .23 \\
Age & $1.02(0.98-1.07)$ & .29 \\
SAPS II & & \\
One-Year Mortality & $1($ reference $)$ & \\
Simple or difficult weaning & $1.80(0.71-4.60)$ & .22 \\
Prolonged weaning & $1.00(0.95-1.05)$ & .89 \\
Ventilation duration before weaning & $1.02(0.99-1.05)$ & .20 \\
Age & $1.01(0.99-1.04)$ & .37 \\
SAPS II score & & \\
& & \\
\hline ICU = intensive care unit & & \\
SAPS = Simplified Acute Physiology Score & & \\
\hline & & \\
\hline
\end{tabular}

nonsignificant trend $(P=.08)$ toward interaction between age and ICU mortality.

\section{Discussion}

The 2005 international consensus conference on weaning from mechanical ventilation ${ }^{11}$ proposed a new classification system based on the difficulty and duration of weaning. In our study, applying that classification system to patients ventilated for more than 48 hours found significant differences in ICU mortality and hospital mortality
Table 5. Logistic Regression Analysis of Weaning Category Versus One-Year Mortality

\begin{tabular}{lcc}
\hline \hline Simple weaning & 1 (reference) & $P$ \\
Difficult weaning & $1.83(0.63-5.33)$ & .26 \\
Prolonged weaning & $2.61(0.82-8.35)$ & .11 \\
\hline
\end{tabular}

between the classification groups, thus confirming the system's clinical relevance. We also found that prolonged weaning is an independent risk factor for ICU and hospital mortality. However, weaning category did not impact oneyear mortality.

The international consensus conference jury estimated the proportion of patients in each group and the outcomes of patients, based on weaning studies. ${ }^{11,15-21}$ All of these studies, except the one by Farias et al, ${ }^{19}$ which was in a pediatric ICU, had inclusion criteria similar to ours. The studies also had similar criteria for passing an SBT and for assessing the resolution of the underlying cause of respiratory failure. The international consensus conference jury found that simple-weaning patients represented approximately $69 \%$ of the overall patients. ${ }^{11}$ They also considered that the Esteban et $\mathrm{al}^{18}$ and Brochard et $\mathrm{al}^{15}$ studies' survival curves indicated that about half the patients who failed the first SBT were still ventilated at day 7 . Therefore, the jury estimated that about $15 \%$ would be prolonged-weaning patients and about $15 \%$ would be difficult-weaning patients. ${ }^{11}$ Our results were very different from those estimates; we found a lower proportion in the simple-weaning group (27\%). One explanation might be our inclusion criteria.

In a recent prospective study, Funk et al ${ }^{12}$ determined for the first time the incidence and outcome of weaning according to the new categorization system. They included all patients who required mechanical ventilation and who started weaning. The cumulative incidence of simple, difficult, and prolonged weaning were 59\%, 26\%, and $14 \%$, respectively. If we had included all patients, including those who required mechanical ventilation for less than 48 hours, as Funk et al ${ }^{12}$ did, our proportions would have been $54 \%, 26 \%$, and $19 \%$ for the simple, difficult, and prolonged weaning groups, respectively, which is much closer to the results of Funk et al. ${ }^{12}$

However, most of the studies used to estimate the incidence of each weaning group evaluated patents ventilated for more than 48 hours, ${ }^{16,19-21}$ or more than 24 hours. ${ }^{18}$ The major difference in the size of the simple-weaning group is probably related to the design of the weaning protocol. In those studies, predictors of weaning outcome were used as criteria for passing SBT. Weaning was only begun when the rapid shallow breathing index (RSBI) did not exceed 105 breaths $/ \mathrm{min} / \mathrm{L},{ }^{21}$ or if after 3-5 min of spontaneous ventilation the patient had at 


\section{Clinical Relevance of Classification According to Weaning Difficulty}

least two of the following criteria: respiratory rate less than $35 \mathrm{breath} / \mathrm{min}$, maximum inspiratory pressure below $-20 \mathrm{~cm} \mathrm{H}_{2} \mathrm{O}$, or tidal volume over $5 \mathrm{~mL} / \mathrm{kg}$ predicted body weight. ${ }^{16-18,20}$

Tanios et $\mathrm{al}^{22}$ evaluated the influence of including a weaning predictor in a daily weaning readiness screening. They included 304 patients, of whom 151 directly passed the SBT regardless of their RSBI, and 153 patients passed only if RSBI did not exceed 105 breaths/ $\mathrm{min} / \mathrm{L}$. Ninety percent of the patients had successful extubation when the researchers used the RSBI as an SBT-readiness criteria, versus $70 \%$ without RSBI prior to the SBT. The re-intubation rate was similar in the 2 groups. The use of weaning-readiness predictors therefore seems to increase the probability of successfully passing the first SBT and could thus increase the probability of classifying patients in the simple-weaning group. However, if no differences were found considering ventilation duration, weaning began later in the RSBI group. The American College of Chest Physicians $^{23}$ and the Société de Réanimation de Langue Française $^{24}$ consensus conferences did not recommend the inclusion of weaning predictors, considering the efficiency and safety of a properly monitored SBT. No data suggest that SBTs contribute to any adverse outcomes if terminated promptly when failure is recognized. ${ }^{25}$ In our study we did not use any weaning predictors in assessing readiness for the first SBT, so SBTs began earlier and therefore had a lower probability of successful first SBT. Considering the definitions of the 3 groups from the consensus conference, we probably overestimated weaning difficulty, compared to studies that used weaning predictors, which may have contributed to our low incidence of patients in the simple-weaning group. Weaning duration was quite short in our difficult-weaning and prolonged-weaning groups $(2.7 \mathrm{~d}$ and $8.6 \mathrm{~d}$, respectively), whereas, according to the definition, difficult weaning lasts as long as 7 days. Our extubation failure rate was $7 \%$, which corresponds to the optimal reported re-intubation rate of $5-15 \% .{ }^{23}$

Another explanation for our low rate of simple-weaning patients might be the heterogeneity of illness severity in the included patients. Perren et al included patients with a mean Simplified Acute Physiology Score (SAPS) II score of 45, and $85 \%$ patients belonged to the simple-weaning group. Their overall ventilation duration was shorter than ours ( $3.5 \mathrm{~d}$ vs $7.6 \mathrm{~d}),{ }^{21}$ which may be related to lower illness severity. In other studies, including the one by Esteban et al, ${ }^{16-18}$ the mean SAPS II score range was $19-37$, as compared to $54 \pm 17$ in our cohort.

Our mortality rates were lower than we expected based on the SAPS II scores and the mortality predicted by the consensus conference jury, ${ }^{10}$ who predicted in-hospital mortality at $12 \%$ in the simple-weaning group and $36 \%$ in the difficult-weaning and prolonged-weaning groups, compared to $0 \%, 10 \%$, and $22 \%$, respectively, in our study. ${ }^{11,17,20}$ Considering the results of 2 studies, ${ }^{11,17,20}$ the jury also predicted higher ICU mortality than we observed: $5 \%$ in the simple-weaning group ( $0 \%$ in our study) and $25 \%$ in the difficult-weaning and prolonged-weaning groups (2\% and 19\%, respectively, in our study). Even though weaning-group impact on mortality may have been overestimated, there were significant differences in ICU and hospital mortality between the 3 groups. In their recent study, Funk et al reported similar results: ICU mortality of $3 \%, 1 \%$, and $22 \%$, respectively, and hospital mortality of $13 \%, 9 \%$, and $32 \%$, respectively, in the simple, difficult, and prolonged weaning groups. ${ }^{12} \mathrm{We}$ also found that difficult weaning was not associated with higher mortality compared to simple weaning, and that prolonged weaning was an independent factor for higher ICU and hospital mortality.

However, there were no differences in one-year mortality between the 3 groups, particularly when considering only the hospital survivors (one-year mortality of $22 \%, 26 \%$, and $25 \%$, respectively, for the simple, difficult, and prolonged weaning groups). Neither difficult weaning nor prolonged weaning was an independent factor for greater hospital mortality. Though the prolonged-weaning patients (versus the simple or difficult weaning patients) had a 1.83 odds ratio of one-year mortality, and the prolonged-weaning patients (versus the simple-weaning patients) had a 2.61 odds ratio of one-year mortality, those differences were not statistically significant. The worse one-year mortality in the prolonged-weaning group is probably due to their higher hospital mortality. According to the literature, the oneyear mortality range in mechanically ventilated patients is $50-70 \%,{ }^{26-28}$ and $63-78 \%$ in patients in weaning units. ${ }^{29,30}$ These results confirm that mechanical ventilation weaning duration does not influence long-term outcome, as already suggested by Stauffer et al, ${ }^{27}$ who found that long-term outcome was independent from overall ventilation duration.

\section{Limitations}

The main limitation of this study is certainly its retrospective and single-center design. Therefore, our results might not apply to other ICUs with different weaning and sedation practices. However, this limitation is mitigated by the fact that we routinely used standardized weaning and sedation protocols prior to patients' admission. A prospective multicenter study would, however, be interesting, at least to validate such a difference within groups in terms of prognosis.

The second major limitation is that we considered only patients who received $\geq 48$ hours of mechanical ventila- 


\section{Clinical Relevance of Classification According to Weaning Difficulty}

tion, instead of including all ventilated patients. However, that inclusion criteria was also chosen in several previous clinical studies on weaning protocols. In fact, in 4 studies taken into consideration by the jury, the included patients were ventilated for more than 48 hours. ${ }^{16,19-21}$ In one study ${ }^{18}$ the patients were ventilated for more than 24 hours, and another study ${ }^{17}$ included all ventilated patients (ie, no minimum ventilation duration). Within our database, $70 \%$ of all patients admitted for toxic coma, and $64 \%$ of all patients admitted after scheduled surgery, required less than 48 hours mechanical ventilation and were promptly extubated (data not shown). In those patients, weaning was very simple, and comparison to patients who required more than 48 hours of ventilation could have been considered artificial, so we excluded those patients.

\section{Conclusions}

Our results confirm the clinical relevance of the new weaning classification system, ${ }^{11}$ which accurately depicts the different ventilated patient populations in an ICU, whatever the overall ventilation duration and the initial severity score. In patients ventilated more than 48 hours, prolonged weaning is a strong independent risk factor for ICU and hospital mortality. There was a trend toward higher oneyear mortality in the difficult-weaning and prolongedweaning groups. A larger study might find a significant difference.

\section{REFERENCES}

1. Chastre J, Fagon JY. Ventilator-associated pneumonia. Am J Respir Crit Care Med 2002;165(7):867-903.

2. Cook DJ, Walter SD, Cook RJ, Griffith LE, Guyatt GH, Leasa D, et al. Incidence of and risk factors for ventilator-associated pneumonia in critically ill patients. Ann Intern Med 1998;129(6):433-440.

3. Fagon JY, Chastre J, Domart Y, Trouillet JL, Pierre J, Darne C, et al. Nosocomial pneumonia in patients receiving continuous mechanical ventilation. Prospective analysis of 52 episodes with use of a protected specimen brush and quantitative culture techniques. Am Rev Respir Dis 1989;139(4):877-884.

4. Langer M, Cigada M, Mandelli M, Mosconi P, Tognoni G. Early onset pneumonia: a multicenter study in intensive care units. Intensive Care Med 1987;13(5):342-346.

5. Dasta JF, McLaughlin TP, Mody SH, Piech CT. Daily cost of an intensive care unit day: the contribution of mechanical ventilation. Crit Care Med 2005;33(6):1266-1271.

6. Wagner DP. Economics of prolonged mechanical ventilation. Am Rev Respir Dis 1989;140(2 Pt 2):S14-S18.

7. Ely EW, Baker AM, Dunagan DP, Burke HL, Smith AC, Kelly PT, et al. Effect on the duration of mechanical ventilation of identifying patients capable of breathing spontaneously. N Engl J Med 1996; 335(25):1864-1869.

8. Esteban A, Alía I, Ibañez J, Benito S, Tobin MJ, Spanish Lung Failure Collaborative Group. Modes of mechanical ventilation and weaning: a national survey of Spanish hospitals. Chest 1994;106(4): 1188-1193.

9. Esteban A, Anzueto A, Frutos F, Alía I, Brochard L, Stewart TE, et al. Characteristics and outcomes in adult patients receiving mechan- ical ventilation: a 28-day international study. JAMA 2002;287(3): 345-355.

10. Kollef MH, Shapiro SD, Silver P, St John RE, Prentice D, Sauer S, et al. A randomized, controlled trial of protocol-directed versus physician-directed weaning from mechanical ventilation. Crit Care Med 1997;25(4):567-574.

11. Boles JM, Bion J, Connors A, Herridge M, Marsh B, Melot C, et al. Weaning from mechanical ventilation. Eur Respir J 2007;29(5): 10331056

12. Funk GC, Anders S, Breyer MK, Burghuber OC, Edelmann G, Heindl $\mathrm{W}$, et al. Incidence and outcome of weaning from mechanical ventilation according to new categories. Eur Respir J 2010;35(1):88-94.

13. Tonnelier JM, Prat G, Le Gal G, Gut-Gobert C, Renault A, Boles $\mathrm{JM}$, et al. Impact of a nurses' protocol-directed weaning procedure on outcomes in patients undergoing mechanical ventilation for longer than 48 hours: a prospective cohort study with a matched historical control group. Crit Care 2005;9(2):R83-R89.

14. Ramsay MA, Savege TM, Simpson BR, Goodwin R. Controlled sedation with alphaxalone-alphadolone. BMJ 1974;2(5920):656659 .

15. Brochard L, Rauss A, Benito S, Conti G, Mancebo J, Rekik N, et al. Comparison of three methods of gradual withdrawal from ventilatory support during weaning from mechanical ventilation. Am J Respir Crit Care Med 1994;150(4):896-903.

16. Esteban A, Alía I, Gordo F, Fernández R, Solsona JF, Vallverdú I, et al; Spanish Lung Failure Collaborative Group Extubation outcome after spontaneous breathing trials with T-tube or pressure support ventilation. Am J Respir Crit Care Med 1997;156(2 Pt 1):459-465.

17. Esteban A, Alía I, Tobin MJ, Gil A, Gordo F, Vallverdú I, et al; Spanish Lung Failure Collaborative Group. Effect of spontaneous breathing trial duration on outcome of attempts to discontinue mechanical ventilation. Am J Respir Crit Care Med 1999;159(2):512518.

18. Esteban A, Frutos F, Tobin MJ, Alía I, Solsona JF, Vallverdú I, et al; Spanish Lung Failure Collaborative Group. A comparison of four methods of weaning patients from mechanical ventilation. N Engl J Med 1995;332(6):345-350.

19. Farias JA, Retta A, Alía I, Olazarri F, Esteban A, Golubicki A, et al. A comparison of two methods to perform a breathing trial before extubation in pediatric intensive care patients. Intensive Care Med 2001;27(10):1649-1654.

20. Vallverdú I, Calaf N, Subirana M, Net A, Benito S, Mancebo J. Clinical characteristics, respiratory functional parameters, and outcome of a two-hour T-piece trial in patients weaning from mechanical ventilation. Am J Respir Crit Care Med 1998;158(6): 1855-1862.

21. Perren A, Domenighetti G, Mauri S, Genini F, Vizzardi N. Protocol-directed weaning from mechanical ventilation: clinical outcome in patients randomized for a 30 -min or 120 -min trial with pressure support ventilation. Intensive Care Med 2002;28(8):10581063.

22. Tanios MA, Nevins ML, Hendra KP, Cardinal P, Allan JE, Naumova $\mathrm{EN}$, et al. A randomized, controlled trial of the role of weaning predictors in clinical decision making. Crit Care Med 2006;34(10): 2530-2535.

23. MacIntyre NR, Cook DJ, Ely EW Jr, Epstein SK, Fink JB, Heffner $\mathrm{JE}$, et al. Evidence-based guidelines for weaning and discontinuing ventilatory support: a collective task force facilitated by the American College of Chest Physicians; the American Association for Respiratory Care; and the American College of Critical Care Medicine. Chest 2001;120(6 Suppl):375S-395S.

24. XXIème conférence de consensus en réanimation et médecine d'urgence: sevrage de la ventilation mécanique. Réanimation 2001; 10:697-698. Article in French. 


\section{Clinical Relevance of Classification According to Weaning Difficulty}

25. Ely EW, Baker AM, Evans GW, Haponik EF. The prognostic significance of passing a daily screen of weaning parameters. Intensive Care Med 1999;25(6):581-587.

26. Douglas SL, Daly BJ, Gordon N, Brennan PF. Survival and quality of life: short-term versus long-term ventilator patients. Crit Care Med 2002;30(12):2655-2662.

27. Stauffer JL, Fayter NA, Graves B, Cromb M, Lynch JC, Goebel P. Survival following mechanical ventilation for acute respiratory failure in adult men. Chest 1993;104(4):1222-1229.
28. Chelluri L, Im KA, Belle SH, Schulz R, Rotondi AJ, Donahoe MP, et al. Long-term mortality and quality of life after prolonged mechanical ventilation. Crit Care Med 2004;32(1):61-69.

29. Schonhofer B, Euteneuer S, Nava S, Suchi S, Kohler D. Survival of mechanically ventilated patients admitted to a specialised weaning centre. Intensive Care Med 2002;28(7):908-916.

30. Carson SS, Bach PB, Brzozowski L, Leff A. Outcomes after longterm acute care. An analysis of 133 mechanically ventilated patients. Am J Respir Crit Care Med 1999;159(5 Pt 1):1568-1573.

This article is approved for Continuing Respiratory Care Education credit. For information and to obtain your CRCE

(free to AARC members) visit www.RCJournal.com

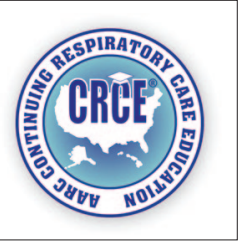

